\title{
Carne de castilla
}

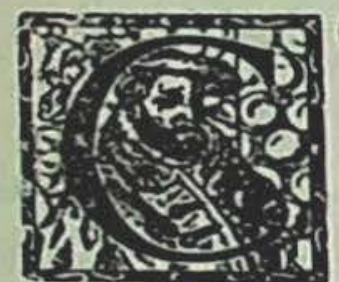

ONOCI realmente a Onofre Salinas cuando vino a vivir al fundo, comprado a un tío o primo hermano suyo, en la cordillera de la costa, casi al borde del valle central - mejor dicho, el valle central penetraba la cordillera como una impetuosa ola de verdura y humedad.

El fundo de Salinas colindaba con el de mi padre y era gemelo por las características de la tierra y de la gente que los poblaba desde la colonia.

Cerros unidos entre sí, como un oleaje hecho piedra y en que las cumbres cónicas del Name y del Gupo, espectros de volcanes, son aún los centinelas del paisaje.

Pero en ese enredo de duros perfiles y de faldas interminables, corren arroyos, verdean vallecitos y vegas, convertidas en huertos por los agricultores costinos.

Como un regalo inesperado de la geología parte los cerros el río Purapel con sus aguas perezosas, como que van de mar a cordillera en un alarde de rebeldía o a lo mejor asustadas de ver al mar, a pocas cuadras de su cuna de piedra.

En el valle se alinean como soldados los álamos de Europa, junto a los hualles que han nacido en el mismo sitio en que derribaron a padres y abuelos.

Añosa selva cubrió los cerros, hoy desnudos o partidos en zanjas gredosas, en que el roble no estaba, como en los bosques del sur, codo con codo, sino solitario en las cumbres y faldas. 
Vigoroso candelabro de color rojizo, abrigado en suaves túnicas vegetales y cuyos brazos se dan tan gruesos como el tronco de donde nacían.

De aquí salieron, mediante el hacha amaestrada de los cerrucos, las rodas y codastes de una sola pieza, que, durante medio siglo, hicieron célebres a los faluchos y lanchones maulinos en la costa del Pacífico.

Hoy las champas grises del coirón y la pluralidad de las hierbas del campo, tapizan faldas y cumbres, paraíso de la oveja cerruca, pequeña y andariega, pero cuya carne prieta huele a murtilla y cuya leche es densa como un plenilunio de verano.

Los rincones conservan sus nombres indígenas que tienen más relación con el pasado que con el momento actual.

La tierra de mis padres es Copiulemu, selva de los copihues. Ni selva ni copihues.

Diucalemu, bosque de las diucas, se llama el fundo adquirido por Salinas y su nombre aún tiene justificación.

Hay una quebrada donde pataguas, arrayanes y hualles crecen fraternalmente y donde anidan todos los años miles de diucas.

Los amaneceres de verano no se caracterizan por la luz ni por el rumor de los viejos árboles, sino por el alegre trinar de las diucas. Durante media hora el alba es sólo gorjeo de diucas, elemental, desentonado, pero con la magia agreste de un paisaje cerruco.

Sabía, sin que me lo hubiesen presentado, por amigos comunes, que Salinas era un emigrado reciente, de Palencia y que llegó a Chile con su padre, durante la presidencia de Balmaceda.

Estos palencianos, dueños de viñedos que arruinó la filoxera, fueron contratados por los agentes de emigración con la condición expresa de trabajar en los campos.

Los padres, sí, cumplieron, pero no los hijos.

El mayor y Onofre instalaron en la calle Comercio, de Talca, una gran sombrerería "La villa de Madrid", a la manera de Cohé o de Haudeville, de Santiago. 
Borsalinos y tongos llenaban los anaqueles y en los veranos, los sombreros de paja, de coloreadas cintas, sobre los mostradores, parecían un trigal macollado en una loma fértil y ya se sabe, la abundante clientela la formaban los jovencitos talquinos, atildados y cuidadosos en el vestir, como en ninguna otra ciudad de Chile.

Tenían algo esos talquinos, yo me excluyo por descender de franceses, de aquellos jóvenes de que hablaba el padre Ovalle, poco aficionados al estudio y sí a la vida holgada, dispendiosa que podían llevar con el producto de sus fértiles fundos del valle central. Y este caballero provinciano no es sino un fruto tardío del oligarca santiaguino que viajó a Europa, a París sobre todo, y al volver a su tierra la halló descolorida y miserable.

Onofre no era un tipo de español corriente. Venía en él ya el germen del señorito que ambicionaba ser y por consiguiente, la tienda era para él un estorbo. Su ideal consistía en poseer un fundo valioso y veranear en Constitución.

No buscó sus relaciones entre los señoritos talquinos, algo cursis y con ineptas pretensiones heráldicas, como los pichones Cruz, descendientes del Conde de Maule, judío italiano ennoblecido por el Rey de España.

Se acercó, con evidente tino, a una clase media culta: profesores del liceo, periodistas y a un grupo de intelectuales, a quienes dió relieve Enrique Molina, Alejandro Venegas y más adelante, Enrique Escala.

Sin embargo, no era un hombre culto. Apenas las primeras letras de una escuela de Palencia, pero poseía cierto fervor artístico, una tendencia a discutir las cosas antes de aceptarlas. $\mathrm{Y}$ cuando los amigos le aconsejaban que no deshiciese la sociedad con su hermano, que era un negocio seguro, les respondía con exagerados ademanes y con el tono alto de su timbre de barítono:

-El estar todo el día con el vientre pegado al mostrador (algunos hasta tienen callos ahí); luego, ceder el negocio a los hijos y curarse las várices, sentado en un sillón, no me gusta nada. Es repetir lo que dice Grassi que sucedió, a fines de la colonia. El padre, recién 
llegado de España, trabajaba en una tienda, el hijo se educaba y se convertía en pije y los nietos pedían limosna porque gastaba sin producir.

Grassi, un periodista nato, hijo de italianos y aun creo que nacido en Italia, comprendía muy bien a su país de adopción y a su habitante.

Algo solemne, sin ser cursi, aclaró la idea de Salinas:

- Sí, señor, el padre mercader, el hijo caballero y el nieto pordiosero, en tal forma se repitió el hecho en toda América, explicaba, incluso México, que se cuajó en refrán.

-A mí me gusta el campo, continuó Onofre. El mostrador es como una jaula para el pájaro. Achica el ánimo y aplasta la imaginación, aunque, al final muchos se enriquezcan. Ya le he echado el ojo al fundo de mi tío Eleuterio, porque ninguno de mis primos quiere quedarse en él y el viejo está ya cansado.

- ¿Diucalemu?

-Justo, Diucalemu.

-Entcnces seremos vecinos, Onofre. Mi padre aun trabaja Copiulemu, casi igual al de su tío Eleuterio. Salvo que Diucalemu tiene más agua, es decir más vertientes.

-Pues me alegro de que sea Ud. mi vecino. Si tengo pleitos, me los defenderá.

-No hay inconveniente si me recibo.

$\mathrm{Si}$ he de ser franco, llegaba Onofre Salinas a la vida rural, en la etapa segunda que citaba Grassi, en la del hijo caballero, aunque no hubiese estudiado en liceos y universidades, en cambio, suministraba artículos de lujo, como camisas, corbatas y sombreros a los hijos caballeros de Talca y ésta era la originalidad de su intento.

Físicamente se diferenciaba de otros españoles de Castilla o de Vizcaya que se habían radicado en Talca.

Onofre era un castellano, pero en sus rasgos, en el pigmento dorado de la piel, en el color claro de la cabellera y en la estatura aparecía el godo, el soldado rubio que se hizo agricultor en "Tierra de campos". 
No era propiamente un celtíbero moreno ni un descendiente de árabes, aunque tuviese, también, esa sangre como la mayoría de los españoles.

La liquidación de "La villa de Madrid" se produjo antes de lo que Onofre suponía por la muerte del tío Eleuterio y la ninguna predisposición de los hijos a trabajar en el campo.

Y fué en el verano de ese mismo año, ya en posesión del fundo y por el piño de yeguas chúcaras trilladoras que poseía mi padre, que intimé con él.

Lo hallaba simpático y grata su compañía. Traté de explicarme por qué. No era su inteligencia ni su cultura. Tal vez el espectáculo humano, sobre todo su entusiasmo, algo ingenuo, quizá el contraste de este hombre de los llanos en unos cerros primitivos, que me hacía pensar en los encomenderos que explotaron los bosques con indios esclavos y en los pastizales recién brotadcs, criaron caballos y vacunos.

Era un milagro este colonizador sin coraza que salía de un mostrador de una tienda moderna, en una ciudad de provincia.

En Diucalemu había una viña que cuidó afanosamente el tío Eleuterio, con modestas bodegas, pero con vasijas nuevas y cierto perfeccionamiento, sin modificar los antiguos métodos, en la preparación de los mostos y vinos y con la viña, un piño de ovejas criollas, saltonos y andariegas.

Tan ágil y trepador de cerros, como el piñ̉o era el ovejero que las cuidaba desde hacía medio siglo: don Inocencio Medel, a quien se le conocía en los cerros como don Chencho y los Chenchos llamaban a su familia, mujeres, hombres, que vivían en un rancho al abrigo de una escarpa del cerro. No quedaban sino la abuela, casi centenaria, la mujer, una hija joven, la Uberlinda, y un muchachito Cañiacho, que ayudaban a su padre en la ovejería y en las mínimas faenas rurales del mediero: una viñita y un trigal de loma.

Ropas viejas, overas de remiendos, polvorientas ojotas, un poncho color de camino y la honda de cuero al hombro, pero el rostro tenía nobles líneas, una barba abundante y crespa y unos ojos claros que delataban al lejano ascendiente encomendero. 
La idea de Onofre, al hacerse cargo del fundo, fué dedicarse a la ovejería. Alguien debió aconsejárselo en Talca, pero con ovejas más finas, de mejor raza que el arisco rebaño de don Chencho.

Me habló muchas veces de las ovejas de Magallanes, de los inteligentes perros que las cuidaban. Supe que un hermano de Jorge González el poeta rural de Chile, que vivió muchos años en Tierra del Fuego, le había contado de esas ovejas y de esos perros pastores, traídos de Australia y de Nueva Zelandia.

La idea de Onofre era terminar con las ovejas cerrucas y traer la nueva raza, pero en el Peralillo, Purapel adentro, teníamos un vecino, un huaso del Empedrado, don Rudecindo Jorquera, huaso alegre y dicharachero que se rió, a grandes risotadas, de la idea de nuestro amigo.

Como observó el gesto de cólera contenida de Onofre, lo palmoteó afectuosamente en la espalda y le dijo:

-No, pues, mi amigo, las ovejas de Magallanes se mueren di'hambre aquí en los cerros. Mire el pelaero ahora, y los perros de calor. Son muy lanudos, son pa tierras donde hay nieve. Aquí lo que hace falta es la oveja Chauredón (1) que es más sufrida, aunque tenga menos lana. Claro, hay que terminar con los carneros viejos y traer otros más jóvenes, amigazo.

Fué amigo de don Rudecindo pero no se entregaba por completo a él. Algún móvil, no definido lo defendía. Tal vez la antítesis del caballero y del pícaro.

Huaso dionisíaco, inescrupuloso on Rude, gran bebedor y amigo de la remolienda. Siempre que se le encontraba en los disparejos caminos de los cerros iba montado en lustrosos alazanes o en tordillos de abundante crin, cuando el cerruco cabalgaba en un caballejo, casi siempre mulato, que reproducía en sus ancas puntiagudas el lomo disparejo de los cerros.

(1) Hampshire Down. 
¿De dónde provenían esos caballos de raza, tan bien alimentados?

Nadie lo sabía, ni tampoco lo averiguaba nadie.

Don Rudecindo, campechano, astuto, dadivoso y mezquino al mismo tiempo era como el ideal hecho realidad de cada cerruco, el costino valle centralizado, sin abandonar nunca su oculto ángulo de robles y de vegas.

-Y luego, on Onofre, no escuide la viñita, muy producidora. On Eleuterio le estrujaba muy buen tinto, de mascarlo.

$\mathrm{Y}$ pasaba la lengua por los gruesos labios sensuales y su cara ancha se tornaba más rojiza si cabe.

- Mi tío no hizo sino el vino de Castilla la Nueva, aunque en estos últimos tiempos el caldo de las viñas se lo llevaban los franceses en un barrilito.

El pedazo de valle central, encajado entre los primeros contrafuertes de la cordillera de la costa, pertenecía a un viejo terrateniente costino, don Juan de Dios Maldonado.

El vallecito tenía un mágico nombre mapuche, Antilco, que un misionero capuchino tradujo una vez: agua que brilla al sol.

Don Juan de Dios era padre de dos hijas, a medio desbastar por el colegio de monjas de la Inmaculada Concepción, de Talca.

La mayor se casó con un médico y vivía en el sur. La otra, Mirtala, era una solterona cerril que no había encontrado novio, a pesar de Antilco y de los fundos cordilleranos de Maldonado.

Hablo de esto, porque el malicioso huaso de Peralillo descubrió el juego de Onofre Salinas: casarse con la hija de Maldonado. Y Salinas no lo desmintió.

Recordé, entonces, la broma de Grassi, en los paseos dominicales, en torno a la plaza de Talca, después de la misa de mediodía, en la catedral.

Onofre, elegantemente trajeado, con un flamante jipijapa en la ensortijada cabeza, piropeaba a una niña de la sociedad de Talca, alta, pálida, el óvalo perfecto del rostro enmarcado por el manto de 
espumilla y en la mano, de largos dedos, el rosario de conchaperla y el libro de misa de broche de oro.

Con su voz sorda, Grassi le decía:

- Con una mujer así debes casarte, Onofre. Linda y con fundo, además.

Velozmente recogía el reto Onofre:

- $\mathrm{Ca}$, ca, hombre, ésa lo que quiere es un licenciao.

Sin comunicarle lo que pensaba, le hablé del mal genio de Maldonado y del odio que tenía por los pijes y por los españoles que, para él eran pijes extranjeros.

Se rió con risa sana estrepitosa, claunesca, y repuso:

-Pero ella sí que puede verme a mí, amigo Ulloa.

-Pero una negra tan fea, amigo Onofre.

Intervino don Rudecindo.

-No se ensarte, vecino, me parece que no conoce a las cerrucas. La más flacuchenta tiene escondida su pepita de oro y su moíto de escupir tendrá la Mirtala, cuando on Onofre se le allega. Bien, amigazo, pero el viejo es más agarrao que un clonqui.

Sentíase bien en su descuidada heredad. Le complacía caminar por una tierra, en que árboles, animales y pájaros le pertenecían. Tal vez en esto recordaba a los viejos colonizadores castellanos.

Acentuaba aún más su personalidad de señor rural, más que su terno gastado, polvoriento, la escopeta que llevaba siempre y un bulldog pequeño, fortacho, de los llamados franceses, de un color gris aterciopelado, que no se le despegaba de los talones.

El perro le llamó mucho la atención a don Rudecindo:

-Oiga, on Onofre, nu'es ná pa poner reparos. ¿Y onde esenterró ese ñato?

-No lo mire tan a huevo, on Rude, qu'es de la crianza del vasco Lafourcade, en Colín. Bueno pa los zorros y conejos.

-Pero ése come más que un león, on Onofre.

-Así es, pero es leal camarada. Me acompaña a todas partes.

En el fondo, Onofre concebía al señor, al terrateniente, con su escopeta terciada y su perro a la zaga. 
- ¿Y cómo lo mienta al ñato, on Onofre, si nu'es intrusidá?

-Ah, dijo dándose importancia, se llama don Suero de Quiñones, pero on Chencho lo llama Suero, no más. Debe creer que es el suero de la leche.

- Perdone, on Onofre, pero yo tampoco conozco otro.

-Es que este perro recuerda al caballero del Puente Orbigo, que desafiaba a pelear a todo el que llegaba por ahí y no lo permitía el paso sino decía que su dama era la más hermosa y la más honesta de toda Castilla.

Rió a boca abierta, con roja risa el huaso.

- Este on Onofre!

Y la gorda pantorrilla, con su enorme espuela, que él colocaba en el arzón de la silla (no se bajaba del caballo así no más) para descansar, tomó su posición normal y la punta de la bota enfocó diestramente el estribo de roble.

-Adiós, on Onofre, que le vaiga bonito y ojo con el veterano que tiene más mañas que pingo resabiado.

Pocos días más tarde, supe en Talca por Grassi y el poeta Ríos Madrid, que un mozo de Antilco había encontrado en un montecito de hualles el caballo de Onofre. Fué avisado el viejo y hubo un violento tiroteo de palabras entre el palenciano y don Juan de Dios y algunos días después, Mirtala, que era mayor de edad, huyó de su casa para casarse con Onofre.

Don Rudecindo, Grassi, Ríos Madrid y yo fuimos sus testigos en la ceremonia civil.

Ya en el campo, conocí mejor a la hija de Maldonado. En Talca era como cualquiera señoritinga provinciana. No me pareció que poseyese en absoluto el moíto d'escupir, a que hizo alusión don Rudecindo Jorquera. Ni creo que se diese cuenta que se casó con un hombre de cierta personalidad y además, buenmozo. Fué el primero que la solicitó formalmente y dijo que sí, quizá por el miedo de quedarse soltera. 
Hablaba poco y cierto estrabismo daba la impresión de que había perdido la mirada. En las conversaciones, salvo algún cambio de palabras con su marido, no hablaba.

En la vida solitaria del campo, ya conocidos hombres y parientes, la cercanía de un vecino como Onofre Salinas, era agradable y me distraía.

Con frecuencia, en las tardes, sabía que a esa hora estaba en la casa, solía visitarlo. No tengo para qué explicar que nuestra intimidad era cada vez mayor, sobre todo en un extravertido como mi amigo castellano.

Recién casado y buscando torcazas en la quebrada de Diucalemu, fué más explícito en sus confidencias.

-Ahora, amigo Ulloa, hay que hacer aflojar la mosca al viejo, pero no rogándolo, sino obligándolo por el corazón.

- ¿Por el corazón? Si ese viejo en lugar de corazón tiene un cuesco de lúcuma.

Habíamos encontrado, como de costumbre a don Rudecindo en el camino. El vaso de vino de Diucalemu lo atraía embrujadoramente. Rondaba siempre a esa hora por los cerros en cabalgatas indecisas.

- ¿Y cuál es la trampa que le va a armar si se puede saber?

-Un nieto, dijo Onofre, mirándonos con cierto aire de desafío. $\mathrm{Ni}$ don Rudecindo ni yo contestamos nada, pero pensábamos: ¿Y si el nieto no llegaba o el viejo no se conmovía?

Onofre pareció adivinarlo, porque respondió:

- Los Salinas somos melliceros y el viejo no tiene todavía ningún nieto.

Le gustaba asimilar los dichos campesinos, pero nunca lo vi vestido de huaso, a pesar de que en una cómoda (me las mostró en una ocasión) guardaba cuidadosamente mantas y chaquetas de huaso y en unos clavos colgaban espuelas de refulgentes rodajas; sin embargo, él usaba unos espolines mohosos y unas polainas sin lustrar sobre pantalones recogidos en la pierna. 
$\mathrm{Y}$ al verme un día con botas y pantalones de montar y relucientes espolines ingleses, me dijo burlonamente:

-Ese es traje de patrón, mi amigo Ulloa. Alguna vez me pondré yo mis pilchas de huaso.

- ¿Cuándo seas dueño de Antilco?

Tenía el sentido del humor:

-Entonces. ¿No te parece?

Esa tarde nos acercamos al estero de Diucalemu, donde estaba la ovejería. El piño recorría los cerros, seguramente, porque no se divisaba ninguna os eja ni se veía a los ovejeros.

La orilla del estero a donde habíamos llegado cazando torcazas y tórtolas la cubría un montecito de pataguas y sauces, con el varillaje desnudo y ceniciento en esa época del año.

La orilla opuesta, la de la ovejería, era parda y más alta. Sólo un viejo espino crispada su ramazón gris en la fría inmovilidad del aire. Lo miramos como si nunca lo hubiéramos visto. En tal forma nos impresionó con su ramaje torcido, resumen del paisaje invernizo de los cerros.

Don Rudecindo nos explicó:

-El espinito ese, tan viejo como el cerro, tiene su historia. Lo llaman el espino de las calaveras. Antes, cuando moría de frío algún corderito, el ovejero lo tiraba al árbol para que lo viese el patrón. Ahí se podría, si no se lo comían los jotes y los ratones. Ha de quedar todavía alguna cabeza.

El Diucalemu y hay que hablar de él, porque tenía tanta personalidad como un cerruco, no se caracterizaba por la abundancia de sus aguas, salvo en las avenidas de inviernos muy lluviosos. Su encanto residía en el silencio de sus aguas, que parecían regalonear con la arena amarilla y dormitar en los remansos, donde el coipo y el dueño del agua de la leyenda popular vivían sin malquistarse, sin rivalizar en lo más mínimo y hasta tal vez sin conocerse.

En el rubio reposo de estas arenas blanquean trozos de cuarzo que guardan en sus huecos granos de oro, como muelas de una man- 
díbula, desprendida del cráneo de un gigante que hubiera vivido en el corazón de la tierra.

Don Rudecindo dió más noticias:

-Dicen que el viejo Chencho tiene una botella litrera, llena hasta la mitad de pepitas de oro, recogidas en el estero.

- Son tuyas, Onofre, le dije en broma.

Rió Onofre y repuso:

-Pero yo no he hecho ninguna petición de mina.

Al vadear el estero y subir a la planicie, salpicada con las duras bolitas negras que forman el excremento de las ovejas, vimos, en el extremo de una escarpa, el viejo rancho de don Chencho con la cepas retorcidas de la viña y la abuela temblona, sentada en la puerta del rancho.

-Estos Chenchos son más viejos que los cerros —comentó don Rudecindo.

- Todavía tiene una vaquillona que puede darle buena cría, dijo Onofre.

-Ya le echó el ojo a la Uba - bromeó don Rudecindo.

En ese instante, el perro bulldog que nos acompañaba, se apartó de su amo y corrió en la planicie, desatentado, enloquecido, husmeando como si olfatease un peligro.

-Algún zorro que ha olisqueado, explicó don Rudecindo.

-A lo mejor, anoche se sintió el huac huac, según Cañiacho, pero no se le pudo ubicar.

Volvimos a las casas a comernos un costillar de cordero con sabroso y picante pebre de cilantro y cebolla y buenos tragos del vino tinto que tanto gustaba a don Rudecindo.

A Onofre le costó mucho convencerse de la eficacia de los perros del ovejero, en el piño de ovejas Hampshire Down con dos carneros que acababa de comprar. Los encontraba flojos y distraídos.

Uno, el Cholo, negro, escurridizo, manejaba el piño como un buen jinete las riendas de su cabalgadura; el otro, el Viruta, por su 
cola enroscada y por su color bayo era ancho, de mal genio, pero incansable en la vigilancia de los corderos.

Ante el desprecio del patrón por los perros cerrucos, el Chencho los elogiaba:

-No, patrón, decía pasándose el dorso de la mano por su barba mojada, son muy peritos. $\mathrm{Ni}$ bestia ni hombre se allegan al piño y eso que las zorras paridas andan esperecías di'hambre.

Onofre tenía una reacción muy semejante ante don Rudecindo y el ovejero. El las llamaba, las atajadas cerrucas, riéndose, pero finalmente aceptaba los consejos del propietario y del inquilino.

Ahora preocupaba a $\mathrm{mi}$ amigo su falta de fondos, aunque el Banco Español de Talca le hubiera concedido un sobregiro.

-De repente hay que cubrirlo y ahí vienen los apuros, refunfuñaba.

Debía, también, la última cuota del fundo. $Y$ desde luego, no esperaba la ayuda del suegro, con el cual no tenía relación de ninguna especíe. Ni deseaba su muerte (era un creyente nato, como buen español) y luego si lo pensó un segundo, se reía, porque Maldonado era un viejo maitén de los cerros, de pertinaz verdor y de entraña incorruptible. Sólo una catástrofe, rodado o temblor podía derribarlo.

Pero en el palenciano predominaba el optimismo. No representaba el lado severo y tenaz del castellano, sino cierta alegría, una embriaguez dionisíaca que es frecuente entre los españoles. Confiaba más en el orgullo del viejo, al saberse abuelo (aún no lo era) que en lloronas peticiones.

Don Juan de Dios se aferraba a su fortuna, a sus tierras, a sus viñas, a sus animales, con una pasión morbosa que no dejaba cabida para el amor y para la ternura. Esto no lo sabía Onofre aunque lo intuía.

Yo no estaba muy de acuerdo con él, en que se despertase en el viejo alguna oculta veta de enternecimiento, pero no era el instante de contradecirlo. Incluso, al mirar a Mirtala y observar sus caderas, angulosas y su pecho casi sin protuberancias, dudaba igualmente de 
su fecundidad y me resultaba cada vez más lejano el moíto d'escupir de que hablaba don Rudecindo.

Alguna vez asistí durante un almuerzo o unas once, a diálogos como éste:

-A lo mejor esta Mirtala me resulta mostrenca, reía Onofre.

Agresivamente le respondía la mujer:

- ¿Y todavía querís más, coño esperecío?

$\mathrm{Y}$ ella misma desarrugaba el ceño ante las carcajadas de Onofre, celebrando la respuesta de su mujer.

Volví al campo, a principios de septiembre. Olvidé mi curso de Derecho Romano para reponerme en Copiulemu del deficiente almuerzo de la pensión de doña Pepa Rivera, talquina y explotadora, a pesar de sus buenos modales y su sonrisa ronca.

Advertí, al pasar por Diucalemu, que Onofre y su mujer no estaban en el fundo.

Vi el nuevo rebaño de ovejas Chauredón, como decía don Rudecindo $\mathrm{y}$ on Chencho, me dijo complacido:

- Si, su mercé, las niñas se han portado bien y también las gringas que compró el patrón.

On Chencho llamaba las niñas - a las ovejas. Las consideraba como hijas. Conocía sobre todo a las viejas hasta por el balido.

Fuí a Talca algunos días después y encontré una tarde a Onofre Salinas, en la Confitería Palet donde se reunía con Grassi, Jorge González y el poeta Ríos Madrid, que vivía en Talca.

Supe más tarde que Mirtala estaba encinta y vino a Talca con su marido, a consultar a un ginecólogo, el doctor Grassi, hermano del escritor.

Al despedirse, me abrazó cariñosamente y me dijo:

-Mañana o pasado volveremos a Diucalemu. Allá nos veremos ¿no?

-Por supuesto, Onofre, allá nos veremos.

La primavera en las tierras de rulo, en las faldas de los cerros, es una explosión violenta de verdura, de flores anónimas, las corolas policromadas de las miles de hierbas que tapizan durante quince 
días los cerros y luego se agostan y mueren. $Y$ alza su voz el estero, pían los pájaros y chillan los ratones que viven en los huecos de los espinos y sauces. $\mathrm{Y}$ dihueñes descoloridos granulan la piel negra de los hualles. En lo alto planean los jotes. A veces una águila silba en los aires como un bandido que se comunica con un camarada.

En las tierras de riego es suave y continuada, pero sin carácter. Las siembras, pasto o trigo, controladas por el técnico agrícola. El campo civilizado.

Mientras la escarcha se endurece y petrifica en las vegas y valles, se cuaja en niebla casi sólida sobre las planicies de los cerros.

Una mañana, como sucedió muchas veces, apareció Salinas en Copiulemu y se desayunó conmigo.

Mi madre nos sirvió un costillar de cordero, asado a fuego lento y una ensalada de dihueñes, porosos, blanduchos, salpicada con las pintas verdeoscuras del pebre de cilantro y luego tragos del vino, color de oro de la región.

-Este no es el tinto de Diucalemu, le observé a Onofre, sirviéndole.

Respondió alegre, desbordado, por algo tan insignificante.

-Pero es el blanco de Copiulemu y se bebió de golpe la copa que tenía frente a él.

Con cierta ingenuidad, que le era característica, hablaba del niño que su mujer iba a dar a luz y de lo que esperaba de este nieto, cuando el abuelo se enterase. Lo decía a toda voz, delante de su mujer y ésta lo miraba con sus ojos desviados y un gesto burlón, parado como una negra mosca, en sus labios gruesos y partidos.

Pero esta mueca despectiva no la advirtió Onofre y bastaba su alegría sonora para que la rústica casa se iluminara de vida y de futuro, a pesar de sus paredes de adobe y de sus ventanas mezquinas, turbias como ojos de vieja.

Pensaba Onofre que su afán de mejorar el tipo de oveja, las cerrucas por las Hampshire Down, lo elevaría en el concepto del suegro.

Yo le respondí: 
-Al revés, creo que va a pensar que pierdes el tiempo. Es un hombre apegado a los más viejos métodos de la cordillera de la costa. Nunca reformó nada.

Cañiacho vino a avisarle esa tarde, a la oración, que las ovejas iban a parir seguramente esa misma noche.

La oveja pare en las noches o con amaneceres fríos y lluviosos.

Onofre estaba alegre, eufórico. Bebió vino en abundancia y luego algunas copitas del buen aguardiente de los cerros, destilado a espaldas de la ley de alcoholes, en un escondrijo del monte.

Quiso bailar con su mujer, pero ésta lo rechazó con un brusco alzamiento del codo, como protegiéndose de algo. Terminó por dar saltos en torno de ella con muecas exageradas de actor cómico, al mismo tiempo que cantaba:

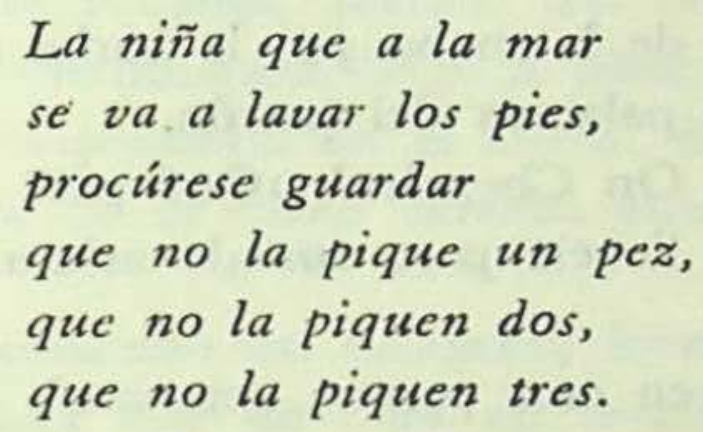

Y levantaba, uno después de otro, los dedos de su mano derecha, para que coincidiesen con los últimos versos de la copla.

A las nueve de la mañana salimos de la casa en dirección al cerro de Diucalemu.

El aire era frío, tenía gusto a escarchilla, según dijo Cañiacho. Los cascos de los caballos partían el hielo, endurecido sobre el barro, pero reconfortaba el ver salir de las anchas narices de las bestias chorros de tibia respiración.

Vimos al piño de ovejas, hecho un solo cuerpo, con don Chencho, con la Uberlinda y los perros que parecían contenerlos para que no se dispersasen.

-Algo sucede, me dijo Onofre.

-Así creo, le contesté. 
On Chencho le dijo algo a Cañiacho y éste, con la ayuda de la muchacha, empujó al piño más allá del espino de las calaveras y no fué difícil cerciorarse de lo que había pasado.

Uno, dos, tres, cuatro y hasta diez corderitos recién nacidos formaban un rosario blanco de óvalos inertes sobre la tierra oscura.

Mi amigo, casi gruñendo, a través de sus bigotes escarchados, palabras ininteligibles, se bajó del caballo, cuyas riendas retuve y se acercó al primero de los corderitos. Lo cogió del tronco y lo levantó a la altura de sus ojos. Colgaba la tierna cabecita como la de un niño muerto. Veíanse huellas de fuertes colmillos en la abierta yugular, roja de sangre coagulada. Lo mismo hizo con el segundo y con el tercero, arrojándolos uno tras otro al suelo. Con un grito agudo, rechinante que espantó a los caballos y a los perros llamó a On Chencho.

Pasándose el dorso de la mano por la barba húmeda, como de costumbre, esperaba las palabras del patrón.

- ¿Vió algo usted, On Chencho? ¿Qué pasó en el piño?

-Nada vi, patrón, l'oveja pare cuando aclara o en la noche y los perros no ladraron.

- ¿Y para qué sirven esos perros, entonces?

-Son buenos, patrón, pero los animales del monte son muy astutazos. Zorra nu'es, porque se habría llevado un cordero. Y tampoco jote porque no si'han visto. $\mathrm{Y}$ de pumas, ni mentarlo patrón. Años que no se merecen pu'aquí.

Presa de incontenible furor, Onofre rechinaba los dientes y daba enérgicas patadas al suelo, como un niño rebelde.

On Chencho le seguía explicando impasible:

-Es harto raro, patrón, porque los mordiscos son de una bestia grande y colmilluda. Como de culpeo. Pero si'acabaron también cuantu'há.

De pronto cesó el castañeteo de dientes de Onofre y le preguntó con cierta serenidad:

- ¿Y qué dice usted, On Chencho, de esto?

El viejo, sin mirarlo, contestó despaciosamente: 
- Pa mí, patrón, es un perro cebao. Cuantu'há, en el agua larga, qu'es este mismo estero pillaron uno qu'hizo mucho evoro de corderos en Huilquilemu, de on Ramón Maldonado, el hermano de don Juan de Dios.

Onofre pareció no oírlo y preguntó:

- ¿No será alguno de éstos, don Chencho? y mostraba al Cholo y al Viruta.

-No, patrón. Estos perros están probados. Los crié para ovejeros y ovejeros son. No son ná muy lindos, pero con ellos nu'hay quien se acerque al piño.

Onofre agitaba los brazos y movía las haldas de su poncho de Castilla, como un gran pájaro negro.

- ¿Y entonces cómo no vieron al que degolló a las crías?

-Es qu'esto es brujería, patrón. Yo ivisé un culebrón entre dos luces y le tiré un hondazo, llegó a silbar la pieira y los perros lo siguieron, pero esaparecería en el estero, digo yo.

Pausa. El dorso de la mano derecha otra vez en la boca y en las barbas.

-Esta tierra, continuó on Chencho, levantando la cabeza, está hechizá, patrón, hasta que un cura no levante la maldición. Ende que saltiaron a la bruja de Name y se llevó el toro blanco con cachos di'oro en una ceja de niebla a la cordillera, la tierra, las viñas, las ovejas no proúcen ni pa comer.

-Claro, tú crees en esas patrañas, ¿verdad?

-Y cómo no he de creer, patroncito, si hasta las vertientes se secaron y ni'aguas d'estero corrieron pu'aquí. $Y$ este culebrón puede ser la misma vieja de Name, aunque esté muerta y sepultá en el pantión de Purapel.

$\mathrm{Y}$ fué tan hondo el acento de fe que puso el viejo en sus palabras que apaciguó la cólera del palenciano.

Subió a su caballo y me invitó a que partiéramos. Pareció olvidar a los corderitos mordidos y al culebrón. Y ahora miraba con simpatía a la Uba, la hija de on Chencho, cuyos ojos dorados, casi del color de su piel, como si el sol de los estíos también los hubiese 
tostado, y la niña respondía a estas miradas con gestos pudibundos, casi cómplices, de mujer poseída y gozosa.

Al atravesar el estero, me preguntó de golpe:

- ¿Y usted qué dice de todo esto, amigo Ulloa?

- Con franqueza, Onofre, creo que on Chencho tiene razón en lo del perro cebao. Yo recuerdo algunos casos en Copiulemu, en Huilquilemo, y en otros fundos. Estos perros son muy astutos, muy ágiles y se pierden como fantasmas en las quebradas donde tienen sus refugios.

Meditó unos segundos y luego me dijo:

-Eso debe ser, seguramente, pero si no lo pilla on Chencho el negocio de las ovejas se va al diablo.

$\mathrm{Y}$ enronqueciendo la voz con tono colérico:

-El ovejero por lo menos debe pillarlo. ¿No cree usted?

-Y lo pillará, Onofre, no le quepa duda y ese culebrón que ha entrevisto es el perro cebado que se escapa a la vigilancia del ovejero y a sus propios perros.

No volvió a hablar en el trayecto de los corderitos muertos. Pero de improviso en sus bigotes color miel asomó una sonrisa, entre pícara y satisfecha:

- ¿Se fijó, amigo Ulloa, en la hija de On Chencho?

- Linda la chiquilla. Son una maravilla hasta los veinte o veinticuatro años; luego el campo las deshace y terminan en viejas desdentadas antes de tiempo.

Onofre pareció no oír. Trataba de explicarme algo y no acertaba con las palabras exactas.

-Usted comprende - dijo al fin- mi mujer embarazada, el aire sano, el campo y la comida abundante (me guiñó el ojo al decir esto), le busqué el lado a la chiquilla. Bajaba la cabeza y se restregaba las manos cuando me acerqué y la besé, así, violentamente. Levantó los ojos y con una vocecita de murtilla en almíbar, me dijo:

-Muchas, gracias, patrón, pero mi asombro fué grande, amigo Ulloa, estaba intacta, sin huella de macho.

-Raro es, dije riendo. 
- Tuve que entregarle mi pañuelo para que se lavara en el estero, pero lo interesante y que me hizo recordar a España fué que, terminado el acto, se tapó la cara con las manos, como avergonzada y con voz oscura balbuceó:

- Me deshonró, patrón, - como en una comedia de Lope de Vega. -Y es cierto, comenté, algo de castellano, de extremeño y sobre todo de gallego, hay en los inquilinos de estos fundos cerrucos. $\mathrm{El}$ indio desapareció muy pronto de la región y terminó por predominar el tipo blanco, definitivamente.

Durante el almuerzo, volvió una vez más al tema de los corderitos, del perro cebado y del culebrón de don Chencho. Hacía un esfuerzo diabólico por aparentar indiferencia y su preocupación se convertía casi en un monólogo, olvidado de mí y de su mujer.

-Pediré prórroga... Me la concederán... Claro... Para eso tengo crédito en el Banco Español y mi primo me esperará... Estoy seguro.

- ¿Por qué no? le dije con voz enérgica para alejarlo de su problema.

- AAh! ¿qué dices? Sí, ya sé, perdóname, Ulloa, no hagas caso.

- Perdonado. ¿Por qué no vamos al Peralillo a hablar con don Rudecindo o con mi padre, si quieres?

- Ca, hombre, si ese huaso pícaro, según dicen, se fué al sur a comprar tierras. A comprar tierras, a comprar tierras. Me ca... en San Dies. Aquí llegará con otro caballo. Esta vez de otra pinta. No te quepa duda.

En la tarde de ese día fuimos a visitar, a orillas del Claro, unos hornos de carbón de espino y talhuén que Onofre tenía en medias con un campesino de la región, José Medel, quizá pariente del ovejero.

A esa hora, las seis de la tarde, hacía frío, pero el cielo estaba despejado y claro. Se recortaban, dibujos a tinta china en el aire, las dos cumbres, el Name y el Gupo. 
Jirones de nieblas, detenidas a media falda del Gupo; nieblas enrolladas como un turbante en la cima del Name. Se las mostré a Onofre y le dije:

- Vamos a tener mal tiempo.

- ¿Cómo? Yo creo lo contrario, aunque para las fiestas patrias casi siempre llueve por aquí.

- Mira le contesté, señalándole los cerros: cuando Name se pone tarro y Gupo se pone leva, ni Dios impide que llueva. Así dicen los cerrucos.

Se animaron sus rasgos y rieron sus ojos, a un recuerdo lejano.

-Yo hice mi servicio militar en España, en Andalucía. Cerca de Sierra Morena hay un cerrito y una tarde le oí una cosa parecida a un campesino: cuando Parapanda se pone la montera, llucve, aunque Dios no quiera.

Aparecieron los hornos en el fondo del vallecito como las deformadas rucas mapuches de una reducción. Unas, humeando por todas sus troneras abiertas; otras, a medio descargar, vomitando negros cubos de carbón; algunos ya deshechos, desmoronados, como enormes muelas careadas y largas filas de sacos, apoyándose unas en otras, que entibiaron los ojos de Onofre. Ya el mediero se acercaba y le decía, sacándose respetuosamente el sucio sombrero:

-Buen rinde, patrón, como usted puede ver.

- Me alegro, Medel, porque el carbón me va a calentar el crédito y rió su ocurrencia.

De vuelta me dijo:

-Mañana descansamos y conversamos, amigo Ulloa. Hay una pierna de cordero y queda todavía una media pipa del vino de mi tío.

Pero lo que no esperaba Onofre era la súbita aparición del mítico monstruo que se bebía la sangre de los corderitos de Diucalemu y se esfumaba misteriosamente en el cauce del estero.

Muy temprano, me despertó un violento diálogo, en que predominaba la voz de Onofre Salinas. Volví a dormirme y me despertó esta vez la mujer de don Chencho que me traía una braserada rojeante y chispeadora de carbón y un suculento desayuno de campo. 
Siempre he de recordar este pequeño cuarto de vieja casa rural, de paredes encaladas y viguetería desnuda (aún Onofre no había rehecho la casona).

La luz palidecía al penetrar por la tosca ventana, especie de agujero anguloso, abierto en el grueso muro de adobes, con vidrios sucios y trizados.

Un retrato del padre de Onofre encima del velador, clavado con chinches. Un viejo alto, vestido de oscuro, con un aguileño perfil de moro.

No era su padre, a quien recordaba Onofre, rubio y charlatán, sino a la madre, una mujercita enteca, de ojos verdosos que alcancé a conocer, encogida por el asma y con la boca desbordante de historias y refranes de su tierra de campo y de su lejana aldea valisolitana.

Fumaba un cigarrillo, medio adormilado por las tibias frazadas campesinas, cuando la casona se llenó de gritos, de juramentos en que el: -me c... en San Dies, era el estribillo. Sonaban portazos, pero nadie respondía a esa cólera, salvo un gallo que tocó su corneta en ese instante, como dando la alarma a sus cloqueadoras concubinas.

Algo había pasado y lo sabría dentro de poco. En efecto, puesto el negro poncho de Castilla, húmedo aún de alba, penetró Onofre a la pieza con su ímpetu habitual.

Casi sin respirar, con la voz casi en estado de trance, me soltó este chorro de frases.

-Otra vez el culebrón de don Chencho. Otros diez corderos con su collar de sangre. Y ahora on Chencho, me fisco en San Dies, me echa la culpa, porque no le dí ayer nada a un mocho franciscano que pasó por aquí con una alcancía de lata, en procura de limosna. Me reí algo de él y no le dí nada. Tampoco llevaba nada en el bolsillo. El mocho se asustó y dijo no sé qué. Claro, en mi contra. $\mathrm{Y}$ on Chencho, me sale ahora: - Patrón, es que no hay que reírse de las cosas santas. 
- Santo, on Chencho, ese mocho mugriento, como perro revolcado.

-Es un inocente, señor, y sus rezos nos libran del Malulo.

- ¿El Malulo? ¿Otro animal fabuloso, on Chencho, que degüella corderitos recién nacidos? ¿No es un culebrón entonces? Signo de la cruz de on Chencho y la respuesta: -Es lo mismo, patrón.

En ese momento crujió la pesada puerta y se coló don Suero, tendiéndose junto a las brasas, aún tibias en su lecho de pulchén.

- Hay veinticinco corderos perdidos, sin descontar los que le corresponden a on Chencho.

Se calló algunos segundos y dijo con decisión:

- Lo más acertado es vender las ovejas y los carneros a Jelves, de la Rinconada, que me ofreció al mismo premio, si le vendía algunas. Hoy mismo mando a Cañiacho a la Rinconada.

-Levántate, que todavía tenemos pierna fiambre, pebre recién hecho y dihueñes. $\mathrm{Y}$ el vino del tío ¿ no?

-El tinto de Diucalemu, de mascarlo, como dice on Rude.

Salió Onofre y como un fantasma, casi sin hacer ruido el bulldog.

En el comedor, supe que Cañiacho galopaba ya en dirección a Name, a la Rinconada.

Onofre era un hombre de rápidas decisiones y ya tenía resuelto el problema de la ovejería.

A pesar del refrán meteorológico, el tiempo permaneció claro y estático: escarcha en las mañanas y tibieza reconfortante en las tardes. Arreboles hacia el mar y chirridos de pidenes en el estero. Suaves manifestaciones de una tierra en agonía.

Yo le dije, bromeando:

- La sabiduría cerruca falló, por lo que parece.

El Name y el Gupo, despojados de niebla, mostraban sus masas azules en la atmósfera transparente.

Onofre, muy alegre, daba rienda suelta a su imaginación.

-Anoche pelearon, Ulloa y el tarro y la levita se fueron al dia- 
blo. El Parapanda, en la Sierra Morena, es sólo y se quita la montera cuando se le antoja.

Fuimos esa tarde, por rutina, a la ovejería, en espera de Cañiacho para llevar las ovejas al día siguiente a la Rinconada.

El espino de las calaveras atrajo nuestra atención. Pareció que había fructificado, en tal forma estaba cubierto de pellejos y cabezas colgantes. Supimos que on Chencho siguió la tradición, arrojando los corderos muertos a las ramas de los espinos.

El ovejero con su hija tenía el piño cerca en espera de órdenes del patrón.

- ¿Y los cueros, on Chencho?

-No sirven, patrón, son muy chiquitos y endebles.

Onofre miraba a la chiquilla y una súbita irritación fruncía sus cejas. Daba órdenes algo desatinadas, que el ovejero prometía cumplir, pero yo me dí cuenta que lo que Onofre deseaba era hablar con la chiquilla y convidarla a algún rincón del campo. No fué posible y hubo que volver a la casa.

Sus palabras fueron éstas, después de separar las ovejas que iban a ser vendidas.

- Si Cañiacho llega en la tarde, salimos mañana temprano con el piño.

-A la oración va a llegar, patrón, porque la Rinconada está detrás del Gupo y hay que subir y bajar cerros.

- Mañana o pasado da lo mismo, respondió Onofre, envolviendo con una mirada sensual a la Uba, que disimulaba su turbación, integrando al piño un cordero descarriado, con un gritito agreste, asordinado, que podría transcribirse así: Epa, mañoso, epaaa.

Al atardecer llegó Cañiacho y Jelves aceptó las ovejas al precio convenido.

A las ocho de la mañana del día siguiente, el piño estaba listo para trasladarse a su nuevo destino, otro valle, gemelo al de Diucalemu.

Orillamos la ribera sur del estero para vadearlo en el plan. Dos veces oí la voz del viejo ovejero que espantaba al bulldog, siempre 
metido entre las ovejas, deslizándose como una serpiente, desordenándolas e interrumpiendo la marcha del rebaño.

El Cholo y el Viruta, ágiles, silenciosos, uno que otro gruñido no más, como si fuesen cerrucos transformados en perros, guiaron al rebaño por el vado, algo correntoso a causa de los deshielos.

Al pasarlo, el camino se iniciaba de súbito, perdiéndose como una faja gris en el portezuelo, un ángulo de cerros, para bajar al vallecito de la Rinconada.

Al doblar una escarpa asomó un jinete, borrón oscuro, a contraluz que se fué aclarando a medida que se acercaba. A los pocos minutos se hizo carne y voz. Por su ancha boca salían saludos estrepitosos y movía las manos con las riendas, azorando al caballo, esta vez un retinto, de grueso tronco y poderosos encuentros.

- ¿Y qué anda haciendo on Onofre por estos cerros? ¿Qu'es lo que aguaita si se puee saber?

Apretones de manos, luego. Como siempre, nos detuvimos a conversar. Rápido cambio de bromas entre ellos. Curioso finteo que escondía bajo su apariencia amistosa, una cierta rivalidad entre el huaso auténtico y el español que iniciaba su adaptación al medio rural.

- ¿Y cómo le fué por Mulchén, don Rudecindo? Creo que esa es tierra de buenos caballos, ¿no?

El huaso, según su costumbre, puso su pierna maciza, con gran sonar de rodajas, en el arzón de la silla y le respondió con cierta sorna:

-Buen pasto, buenas vacas, gente la mar de cariñosa, asados al palo a tutiplén, don Onofre, pero llueve tantazo y además el indio, que roba lo que puede $y$ hay que dejarlo robar, hay que darle su maquila, si no se la toma por sí mismo. Prefiero, mirevé, los cerros, mejor aire y las mujeres más mansitas, humildes como brevas maúras. Allá hay que pescarlas con lazo, mirevé.

Y cambiando de tono y ahora con acento más bien serio, preguntó: 
- ¿Y pa ónde lleva ese piño? ¿Que no son las mismas qe compró en la feria de Talca?

- Las mismas, don Rudecindo, pero el culebrón acabó con las crías. Las degolló casi todas. Prefiero venderlas, con los carneros.

- ¿Un culebrón? ¿Di'ónde sacó ese cuento, on Onofre? Usted se está poniendo más cerruco que on Chencho.

-El dice que es un culebrón.

- Qué culebrón ni que lesera! Cuantu'há solían bajar pumas del monte, pero el puma no ataca las crías sino a la oveja. Ese es un perro cebado, mi señor.

-Y bueno. Supongamos que sea un perro cebado. ¿Y dónde está? ¿Quién lo ha visto?

- Hay que buscar el rastro hasta pillarlo. Esto es cosa de paciencia, don Onofre. No creo que a una ánima le guste tanto chupar sangre ¿no?

Onofre llamó a on Chencho y le preguntó a boca de jarro:

-Oye, viejo, ¿no has notado rastro de perro en el cerro?

-Se cruzan rastros, pero son del Viruta, del Cholo y del perro del patrón. Ninguno va pal cerro.

El huaso bajó su pierna (era en él habitual) la encajó en el estribo y alargando el cuello hacia el ovejero le préguntó:

- ¿El perro del patrón? ¿El ñato?

- Sí, su mercé.

Luego buscó al perro y lo vió salir, con su chato hocico, de entre los cuerpos de las ovejas asustadas, se volvió hacia Onofre y le dijo con agria voz, salpicada de agujillas maliciosas y de intenciones ocultas:

-Oiga, on Onofre, será muy elegante llevar ese nato a la cola. ¿Cómo lo llama que se me fué el nombre?

-Don Suero de Quiñones, el del Paso Honroso, on Rudecindo. - Suero, el mesmo. Pa mí que a ese le gusta la carne de Castilla. - ¿La qué?, preguntó amoscado el palenciano.

- La carne ovejuna, como la llamamos por aquí, on Onofre, por los cerros. 
Y dirigiéndose a mí, dijo entre explosiones de risa contenida:

-Bueno, bueno con el cerruco éste, que no sabe ni la nombrá de los corderos. Carne de Castilla, señor, carne de Castilla!

- Y bien, ¿y qué hay con eso?

-Que este ñato es el perro cebao.

-Pero si este perro duerme en el comedor, a dos metros de mi dormitorio. Lo veo noche y día y me sigue a todas partes. No, pus, don Rudecindo... Ahí se le perdió la huella, como dice usted.

-Bueno, don Onofre. Así será, según su itamen, pero ojo con el ñato, que le gusta la carne de Castilla. Me con que le gusta.

Se despidió cón Rudecindo y sin asomo de rencor lo convidó Onofre a almorzar al día siguiente en Diucalemu... para conversar sobre la posibilidad de hallar el rastro del perro cebado.

Durante largo espacio de tiempo, Onofre, como ausente, pareció monologar algo que no se entendía. Miraba al perro, miraba al jinete hasta que éste dobló la escarpa del cerro. A ratos parecía fruncir el entrecejo, con rabia; a ratos, su cara se distendía, abierta, sin muestra de enojo.

No sin sorpresa, le oí la siguiente pregunta:

- ¿Y qué me dice, ahora, amigo Ulloa?

Lo enfrenté con franqueza y decisión:

-Perdóneme, pero creo que don Rudecindo tiene razón. Ya tenía cierta sospecha de On Suero, no tan honrosa como las del Paso.

-Ah. ¿Tú también? ¿Y por qué no me lo dijiste?

-Era inútil, porque quieres a tu perro y lo supones perfecto. $\mathrm{Y}$ fíjate, ese culebrón de color plomizo que vió on Chencho entre dos luces, coincide con el pelo del bulldog.

Sonrió sin responderme y ordenó a on Chencho a toda voz, como en una trilla.

-Vuelta al piño, on Chencho, vuelta al piño. A Diucalemu, de nuevo. 
Durante el trayecto conversamos de cómo debíamos vigilar al perro. La opinión de Onofre era esperar a don Rudecindo hasta el día siguiente.

-No, le repuse, hoy mismo le armamos la trampa a don Suero de Quiñones. Don Chencho nos va a ayudar.

Tenía sentido del humor, porque entendió muy bien mi alusión.

-Yo le puse ese nombre, que cita tanto el poeta Ríos Madrid, cuando discute con Grassi sobre España, porque me pareció que el bulldog era un dechado de lealtad y sumisión al amo, como el escudero de don Suero de Quiñones.

Y cambiando de tono, agregó con expresión de burla:

- Pero si es otro el perro que muerde a los corderos le voy a aplicar al huasamaco de los caballos el dicho de Grassi sobre los pijes talquinos: Aquí en el Piduco hay muchos que se pitan solos como los cigarrillos Bastos.

Cañiacho llevó las ovejas a sus corrales y en el corredor, on Chencho y Onofre planearon lo que debía hacerse.

Se miraron unos segundos, patrón y ovejero. Onofre preguntó por fin:

- ¿Qué propone usted para seguir los pasos del perro? Porque usted no piensa ahora en culebrones, ¿no es así?

Sin mirarlo de frente, le respondió el ovejero sobriamente:

-Culebrón o perro cebado, patrón, es lo mesmo, porque el mesmo daño hacen.

El español pareció entender el eufemismo del campesino y sonrió.

Explicó el viejo:

- Si es el perro del patrón, debe irse, clariando, pal cerro y volver a las casas a ormir su curaera de sangre.

Onofre, que conservaba su rebenque en torno a la muñeca, le clavó los ojos al perro con gesto amenazador, pero on Chencho lo detuvo:

- Ni por nada, patrón, los perros son muy diablos y parece que entendieran lo que uno conversa. 
Después de un silencio, preguntó como si tuviera madurado un plan:

- ¿Y ónde duerme el perro? y esculpe la preúnta.

-Disculpada la preúnta, on Chencho, respondió Onofre, que había recobrado su jovialidad.

Atravesó el corredor hasta llegar a una tinaja rota, casi enterrada en la tierra. Bebedero de gallinas y de pavos.

-Detrás de esa tinaja, en el rincón, on Chencho. Donde están esos cueros.

Onofre volvió a hablar de la traición del perro, convencido ya de su culpabilidad.

- Y yo que pensaba hacerle una casita al asesino. Me c... en San Dies.

Y bruscamente, como era su modalidad:

-Y bien, ¿y el plan, on Chencho?

Habló el viejo como si no tuviera interlocutor, como para sí mismo, con una voz pausada y gris:

-Quean tuavía algunas ovejas, de las gringas por parir y aunque no parieran, el perro cebado va a olisquear, por si acaso. Hay que dormir aquí mesmo y espertar con noche y ver pa ónde corta. Friazas están las noches, pero en aquel rincón me echo, etrás de esos tablones paraos.

-Bien, on Chencho, le voy a decir a mi mujer que le entregue unos cueros y unas frazadas.

-Dios se lo pague, patrón.

$\mathrm{Y}$ debo confesar que este mínimo drama policial que se formaba en torno al bulldog, el precavido espionaje del hechor y luego, la certeza de su culpabilidad, bajo un cielo neblinoso que ya agujearía el silbo de las diucas, me inquietaban en tal forma que en realidad casi no dormí. $Y$ ante el temor de que se olvidase de despertarme mi atolondrado amigo, vi desteñirse la negra tiniebla de la habitación, se agrisaron los muros encalados y el rectángulo del ventanuco recortó un pedazo de alba. 
Me levanté velozmente, sin lavarme casi, me metí a tientas el poncho de Castilla y salí al patio trasero de la casa. Ya venía, en mi busca, Onofre Salinas.

- Vamos andando. El perro salió al primer diucazo y on Chencho detrás de él.

Ya el trinar de las diucas salpicaba el aire. Brotaba de todas partes, de los árboles del pequeño huerto, de los boldos que se amontonaban en un barranco próximo, del aire mismo, con un gotereo interminable y cristalino, sabroso como murtillas otoñales y como su mismo nombre mapuche.

A veces pensaba en la persecución de un bandido y otras veía al perro tal como lo describió on Chencho, culebrón que repta por la tierra escarchada, el rumor sordo del piño de ovejas empavorecidas y el hincarse de los colmillos en las blancas gargantas de los lechones.

Al bajar al hondón, donde corría el riachuelo, el aire cortaba como el filo de un puñal, hería la piel, con agudos puntazos de hielo.

$\mathrm{Y}$ era una emoción nueva quebrar los vidrios de la escarcha y oír el rezongo del estero, como un escalofrío armonioso. Y nueva también la emoción del campo, pisado por nuestras botas y no a lomo de caballo. Nos entregaba su virginidad, a medio desperezarse: el aleteo flojo de un pájaro, entre los matorrales o el vuelo espectral de un guairao que volvía a su escondrijo entre las totoras.

Los caballos y su alentar potente asustan al paisaje y lo alejan de nuestra sensibilidad.

Comenzaba a desplazarse la niebla y se amontonaba en el cauce del estero, embrujada por el correr del agua, de donde nació seguramente.

En una arruga del terreno encontramos a on Chencho, tendido, casi hecho tierra parda. A su señal de apremio, nos tendimos también nosotros.

-Es el perro de su mercé, rezongó. Agarra al corderito del guargüero y lo sacúe, hecho una furia. Y se relame el indino. 
Con la voz quebrada, presa de una cólera incontenible, dijo Onofre.

- ¿Y a dónde está ahora?

- Cañiacho y la Uba están al otro lado. Un silbido es la seña.

Esperamos algunos minutos. Oímos el desplazamiento característico del ganado y un agudo silbido que quebró el aire, frágil como un cristal.

Nos levantamos y subimos a la planicie, donde estaban los corrales. Cañiacho y la muchacha venían a nuestro encuentro.

Cañiacho explicó, con entrecortadas palabras:

-El perro... se fué... al... al... estero, como bala y se... perdió... atrás el Cholo y el Viruta.

La niña no decía nada, pero su aliento hinchaba su curvado pecho y se hacía luz en las doradas pupilas.

- ¿Y qué hacemos ahora?

- Con la venia de su mercé, el perro ya está en las casas. Su mercé sabrá.

Desanduvimos casi al trote el mismo sendero del alba.

Al llegar al corredor, el perro salió al encuentro de su amo, gimiendo regalón y relamiéndose aún la húmeda nariz, donde quedaban coágulos de sangre.

Un gesto de rabia desfiguraba los rasgos de mi amigo, pero vi con asombro que se contenía y murmuraba, a regañadientes, el saludo a su camarada de los cerros. Algo planeaba que no me comunicó. Sólo un gruñido disimulado y un me c... en San Dies, delataron su intensa contención.

Tomamos una taza de café y un guindado. A la Mirtala le regaló su madre una docena de botellas, cuando nos casamos.

- Indicado, mi amigo, le respondí, conozco el guindado de Antilco. Hay muchos guindales y sobre todo buen aguardiente.

Mirtala no apareció por el comedor.

-No quiere que la vean con el vientre hinchado, me explicó Onofre. Coquetería de señoritinga provinciana. En Palencia las mujeres se enorgullecen de su preñez. 
Bebimos nuestro café. Buena falta nos hacía. $Y$ saboreamos el licor. Merece una mínima loa el guindado cerruco. Aguardiente destilado a escondidas en el corazón del monte, que absorbe la agria pulpa, el ollejo y se impregna levemente de la almendra amarga de la guinda, madurando al sol entre las hierbas del campo, como un fruto de la tierra.

-El auténtico amargor que debe tener el guindado, comenta Onofre, empinando vaso tras vaso.

Algo que venía de muy adentro alborotaba su ánimo y lo hacía gesticular y decir frases inconexas.

Otra vez en camino hacia el cerro, ahora dorado del sol primaveral. Todo despierto y vivo. Trinos de lloicas y flautas de zorzales reemplazaban a las diucas madrugadoras. $Y$ aguas que cantan $y$ pataguas repolludas que comadrean, a la orilla del estero, riéndose de los sauces desmelenados.

$\mathrm{Y}$ don Suero a la zaga, soñoliento y confiado.

Al vernos, se acercó don Chencho. Ni miró al perro, poniendo a prueba su paciente astucia de cerruco, a pesar del trastorno que trajo al plácido piño de ovejas que pastoreaba y a su propio piño.

Estaba inmóvil, frente a nosotros, como si esperase una orden. Con voz ronca, autoritaria habló Onofre:

- ¿Tienes ahí tu lazo?

-Sí, patrón, Cañiacho lo tiene.

-Entonces, enlázalo como a una oveja, del cogote y no lo aflojes.

-On Chencho tose, carraspea, manosea su barba y dice humildemente:

-Con la venia de su mercé, el perro lo puee llevar en noviembre Cañiacho pa la cordillera y quitarle la maña. Mientras tanto yo lo tengo bien sujeto con cadena, aquí en el rancho. Puee ser un buen leonero, su mercé. Es perro de presa.

Onofre no aceptó el sensato consejo del ovejero. 
-Usted obedezca, don Chencho, porque los traidores deben morir como traidores. Garrote vil, como en Castilla la Vieja.

Intervine entonces.

- Mátalo de un tiro, y le alargué la pistola.

-No, señor, garrote, rugió con la boca semicerrada, garrote vil. Advertí un extraño diálogo entre la bestia y el hombre: un murmullo donde se mezclaban el furor contenido y un falso tono de cordialidad. Para no alarmar al perro, supuse. El perro, sin embargo, no se acercaba, como si adivinase las aviesas intenciones de su amo.

-Traidor, solapado (voz bronca, agresiva). Venga, perrito, venga. Suero, Suero (aquí la voz se adelgaza). No sabes la que te espera, so ladrón. Me c... en San Dies (ronca, otra vez).

El perro se inclinó, incauto, hacia los ademanes de afecto de Onofre y se aproximó algunos pasos, gimiendo, removiendo el rabo.

Ya, on Chencho, masculló Onofre impaciente.

Y el viejo disparó el lazo, casi recto a la cabeza del bulldog. Pensé que fallaría el tiro para salvarlo o ganar tiempo, pero no. su habilidad proverbial, apresó justamente el ancho pescuezo, tirando el lazo hacia atrás para achicar la lazada.

Preso del miedo y la rabia, el bulldog resistía con todas sus fuerzas, entre gruñidos, al aire su potente dentadura, mordiendo el lazo que lo estrangulaba.

-Cuelga el lazo del espino, en la rama más gruesa, mandó Onofre. Que muera entre los corderillos que asesinó.

Cañiacho tomó el extremo del lazo y lo deslizó sobre el gajo de espino. On Chencho soltó el lazo y se puso al lado de su hijo. No les gustaba la conducta del amo con el perro, pero obedecían con cierta complacencia de técnicos, de conocedores de su oficio en un instante inesperado de la vida de los cerros. Poco a poco iban acercando al bulldog hacia el espino.

Escena de inútil e inhumana teatralidad.

Uberlinda, asustada, se cubría el fresco rostro con sus manos morenas. En los perros ovejeros la reacción fué conmovedora. El 
Cholo, la cola entre las piernas, gemía, oculto por el muro del piño, mientras el Viruta gruñía, colérico, mostrando sus blancos colmillos.

Estaba casi asfixiado por los tirones del lazo, cuando el perro llegó al espino. Una punta de lengua viscosa se asomaba en la comisura izquierda del hocico.

Padre e hijo miraban a Onofre en ese instante.

- Arriba, gritó éste, adivinando lo que los ovejeros pensaban.

$\mathrm{Y}$ en unos segundos el grueso corpachón del bulldog se balanceó en el aire con la angustiosa desesperación de la agonía, hasta quedar quieto, inerte. Parecía más largo y más flaco y la lengua colgaba como un trapo mojado.

On Chencho soltó en ese instante el lazo y el cuerpo azotó la tierra dura.

-Súbalo, don Chencho, gritó Onofre, que se lo coman los jotes y los traros.

Volvió a alzarlo el viejo, anudando el lazo en torno al tronco del espino.

Onofre me invitó a partir. On Chencho dijo entonces:

$-¿ Y$ mi lazo, patrón?

- Ve a buscar el mío a las casas. Te lo regalo, porque el perro va a quedar colgado ahí ¿¿entiendes?

-Sí, patrón, asintió el ovejero.

Al bajar, me sorprendió Onofre con esta observación:

- Son capaces de enterrarlo y convertirlo en mártir como todo el que muere en el campo, por una razón cualquiera.

Nos encontramos, a mitad de camino, con don Rudecindo Jorquera, montado en su lustroso retinto.

Con su humor habitual, comentó, al saber que el perro había sido ahorcado:

- Ve y ¿ por qué no lo mató de un tiro, iñor?

Gravemente, respondió Onofre:

-A los traidores se les aplica el garrote vil.

- ¿Garrote? y ¿qué es eso, on Onofre?

-Estrangularlo, on Rudecindo. 
- ¿Miren, no? Por algo lo habrá hecho usted, on Onofre, qu'es tan letrao. Pero no se aflija, yo le voy a regalar un buen perro cerruco, de esos que levantan perdices y olisquean a las chillas $y$ a los culpeos.

- No, on Rudecindo, le agradezco. Se puede tentar, cuando vea parir las ovejas.

Se rió con sus estruendosas risotadas, a mandíbula abierta y agregó:

- No, señor, a ese perro no va a poer horcarlo, porque le gusta la carne de Castilla ajena. Es nacido y criado en El Peralillo. Sabe distinguir entre la oveja del amo... y las otras.

Una risotada subrayó y le dió relieve a su pícara observación cerruca.

Del libro "Cerrucos", inédito. 